\title{
Healthcare-associated foodborne outbreaks in high- income countries: a literature review and surveillance study, 16 OECD countries, 2001 to $2019^{*}$
}

Idesbald Boone ${ }^{1}$, Bettina Rosner ${ }^{1}$, Raskit Lachmann ${ }^{1}$, Michele Luca D’Errico² , Luigi lannetti ${ }^{3}$, Yves Van der Stede ${ }^{4}$, Frank

Boelaert $^{4}$, Steen Ethelberg ${ }^{5}$, Tim Eckmanns $^{1}$, Klaus Stark ${ }^{1}$, Sebastian Haller ${ }^{1, *}$, Hendrik Wilking ${ }^{1, \star}$

1. Robert Koch Institute, Department of Infectious Disease Epidemiology, Berlin, Germany

2. Istituto Superiore di Sanità, Department of Food Safety, Nutrition and Veterinary Public Health, Rome, Italy

3. Istituto Zooprofilattico Sperimentale dell’Abruzzo e del Molise G. Caporale, National Reference Laboratory for Listeria monocytogenes, Teramo, Italy

4. European Food Safety Authority, Parma, Italy

5. Statens Serum Institut, Infectious Disease Epidemiology and Prevention, Copenhagen, Denmark

* These authors contributed equally.

Correspondence: Idesbald Boone (boonei@rki.de)

Citation style for this article:

Boone Idesbald, Rosner Bettina, Lachmann Raskit, D’Errico Michele Luca, Iannetti Luigi, Van der Stede Yves, Boelaert Frank, Ethelberg Steen, Eckmanns Tim, Stark Klaus, Haller Sebastian, Wilking Hendrik. Healthcare-associated foodborne outbreaks in high-income countries: a literature review and surveillance study, 16 countries, 2001 to 2019. Euro Surveill. 2021;26(41): pii=2001278. https://doi.org/10.2807/1560-7917.ES.2021.26.41.2001278

Article submitted on 24 Jun 2020 / accepted on 25 Mar 2021 / published on 14 Oct 2021

Background: Healthcare-associated foodborne outbreaks (HA-FBO) may have severe consequences, especially in vulnerable groups. Aim: The aim was to describe the current state of HA-FBO and propose public health recommendations for prevention. Methods: We searched PubMed, the Outbreak Database (Charité, University Medicine Berlin), and hand-searched reference lists for HA-FBO with outbreak onset between 2001 and 2018 from Organisation for Economic Co-operation and Development (OECD) countries and HA-FBO (2012-2018) from the German surveillance system. Additionally, data from the European Food Safety Authority were analysed. Results: The literature search retrieved 57 HA-FBO from 16 OECD countries, primarily in the US $(n=11)$, Germany $(n=11)$ and the United Kingdom $(n=9)$. In addition, 28 HA-FBO were retrieved from the German surveillance system. Based on the number of outbreaks, the top three pathogens associated with the overall 85 HA-FBO were Salmonella $(n=24)$, norovirus $(n=22)$ and Listeria monocytogenes $(n=19)$. Based on the number of deaths, L. monocytogenes was the main pathogen causing HA-FBO. Frequently reported implicated foods were 'mixed foods' $(n=16)$, 'vegetables and fruits' $(n=15)$ and 'meat and meat products' $(n=10)$. Consumption of high-risk food by vulnerable patients, inadequate time-temperature control, insufficient kitchen hygiene and food hygiene and carriers of pathogens among food handlers were reported as reasons for HA-FBO. Conclusion: To prevent HA-FBO, the supply of high-risk food to vulnerable people should be avoided. Well working outbreak surveillance facilitates early detection and requires close interdisciplinary collaboration and exchange of information between hospitals, food safety and public health authorities.

\section{Introduction}

Yearly, 23 million foodborne disease illnesses and 5,000 deaths are estimated in the World Health Organization (WHO) European Region, and 41 foodborne Disability Adjusted Life Years (DALYs) per 100,000 population were estimated for the WHO Sub-Region EUR A in 2010 [1]. In Europe, a total of 5,146 foodborne and waterborne outbreaks, including 48,365 cases of illness and 40 deaths were reported to the European Food Safety Authority (EFSA) in 2018 [2]. Vulnerable populations, including elderly patients, immunocompromised patients, children younger than five years old and pregnant women are more susceptible to foodborne infections and are more prone to develop severe courses of disease compared with healthy people [3]. Therefore, healthcare is a setting where foodborne outbreaks (FBO) can cause considerable morbidity and mortality. In $2020,20.6 \%$ of the European Union (EU) population was aged 65 years and older [4]. As the proportion of elderly people is projected to further increase, the share of the vulnerable population as patients in healthcare facilities (HCF) is likely to increase and thereby the risk associated with healthcare-associated foodborne outbreaks (HA-FBO). Personnel (medical and non-medical staff, food handlers etc) of HCF may also be at risk for HA-FBO and be a source of further spread in healthcare settings and elsewhere. This can cause major disruption of services [5].

So far, literature reviews have covered pathogens responsible for HA-FBO, including Salmonella [6], Listeria 
Flowchart showing the data sources to identify healthcare-associated foodborne outbreaks in OECD countries, 2001-2019

Literature review

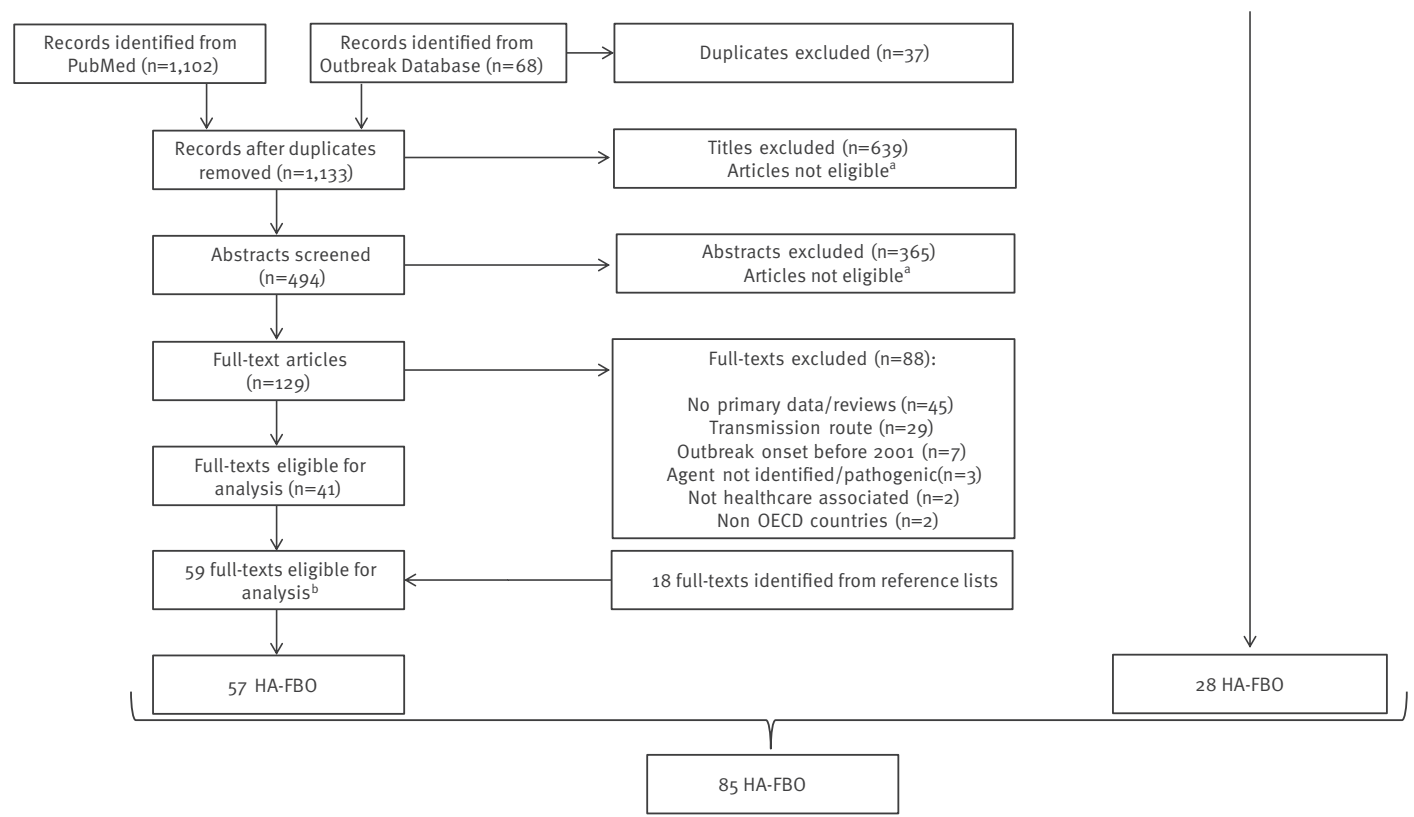

EU Foodborne Outbreak database

ECDC: European Centre for Disease Prevention and Control; EFSA: European Food Safety Authority; EU: European Union; FBO: foodborne outbreaks; HA-FBO: healthcare-associated foodborne outbreaks; OECD: Organisation for Economic Co-operation and Development;

${ }^{\text {a N}}$ Not from a member country of the Organisation for Economic Co-operation and Development (OECD), only community outbreak, pre-2001 outbreak, non-food transmission (person-to-person transmission, contaminated equipment, enteral/parenteral (powdered) formulae), waterborne, caused by histamine poisoning, non-original study (literature review).

${ }^{b}$ Representing 57 HA-FBO, there was one outbreak covered in three publications, one outbreak covered in two outbreaks, and one publication which included two outbreaks.

c One outbreak due to histamine fish poisoning was previously excluded.

monocytogenes [7-9] and norovirus [10,11] and focused on microbiological food safety issues in healthcare settings [5,12]. Between 2014 and 2019, a listeriosis outbreak in Germany affected 13 cases who had an inpatient stay in 12 different HCF during the incubation period [13]. In the United Kingdom (UK) in 2019, nine listeriosis cases of which seven died, had consumed sandwiches in seven HCF during the incubation period [14].

We conducted a literature review to describe the causative agents including bacteria, viruses, parasites and fungi, the incriminated food vehicles and other outbreak characteristics of HA-FBO in 37 countries that are members of the Organisation for Economic Cooperation and Development (OECD) [15]. Furthermore, we analysed German surveillance data and data from the EFSA on HA-FBO. The aim of this article is to describe the current status of HA-FBO in order to improve surveillance and provide public health recommendations for prevention.

\section{Methods}

We defined HA-FBO as: two or more cases of the same disease linked to a healthcare facility (HCF) and epidemiologically linked in place, time and likely to the same food source. Healthcare facilities included hospitals, rehabilitation centres, nursing homes and multiple settings (at least two of the previous categories).

We conducted: (i) a literature review in PubMed on publications between January 2001 and 26 April 2019; and a search for outbreak reports on the Outbreak Database published between January 2001 and 26 April 2019; (ii) an analysis of German national surveillance data on HA-FBO between 2012 and 2018 and; (iii) an analysis of data in the EU foodborne outbreak database managed by EFSA between 2010 and 2018.

\section{Literature review}

We included all outbreaks with outbreak onset between 2001 and 2018 that occurred in a HCF in an OECD country [15] and where foodborne transmission was mentioned. Outbreaks were included regardless of study 


$$
\text { | }
$$


TABLE 2

Top three food categories associated with listeriosis, salmonellosis and norovirus healthcare-associated foodborne outbreaks, by number of outbreaks case-patients and deaths, 16 OECD high-income countries ${ }^{\mathrm{a}}, 2001-2019^{*}$

\begin{tabular}{|c|c|c|c|c|c|c|}
\hline $\begin{array}{l}\text { Number of } \\
\text { outbreaks }\end{array}$ & Reference $^{b}$ & Food categories & Human cases & $\%$ Total cases & Deaths & $\%$ Total deaths \\
\hline \multicolumn{7}{|c|}{ Listeria monocytogenes } \\
\hline \multicolumn{3}{|c|}{ Total } & 176 & NA & 65 & NA \\
\hline 8 & {$[41,46,48,50,77,80,83,86]$} & Food of animal origin & 132 & 75.0 & 50 & 76.9 \\
\hline 8 & {$[57-62]$} & Mixed food & 28 & 15.9 & 8 & 12.3 \\
\hline 2 & [47] & Vegetables/fruits & 13 & 7.4 & 6 & 9.2 \\
\hline \multicolumn{7}{|l|}{ Salmonella } \\
\hline \multicolumn{3}{|l|}{ Total } & 916 & NA & 11 & NA \\
\hline $6^{c}$ & {$[31,45,56,63,87]$} & Food of animal origin & 341 & 37.2 & 8 & 72.7 \\
\hline 3 & {$[36,43,44]$} & Vegetables/fruits & 122 & $13 \cdot 3$ & 0 & 0 \\
\hline 3 & {$[38,75]$} & Mixed food & 118 & 12.9 & o & 0 \\
\hline \multicolumn{7}{|l|}{ Norovirus } \\
\hline \multicolumn{3}{|l|}{ Total } & 1,600 & NA & 1 & NA \\
\hline $4^{\mathrm{d}}$ & {$[64,79]$} & Vegetables/fruits & 748 & 46.8 & 0 & 0 \\
\hline 2 & {$[72,85]$} & Mixed food & 177 & 11.1 & 0 & 0 \\
\hline 2 & {$[33,81]$} & Food of animal origin & 111 & 6.9 & 1 & 100 \\
\hline
\end{tabular}

NA: not applicable; OECD: Organisation for Economic Co-operation and Development.

a With exception of Turkey which is an upper middle-income OECD country.

${ }^{b}$ Reference: Only references to publications listed; for HA-FBO extracted from the German surveillance system SurvNet, see Supplement S1, Table S1.

c One Salmonella Muenchen [38] outbreak associated with raw pork not included (healthcare-associated case numbers not reported).

d One norovirus outbreak [41] associated with frozen strawberries not included (healthcare-associated numbers not reported).

Note: numbers do not add up to n, as only the top three (aggregated) food categories are represented.

design and without language restrictions. Healthcare staff and workers in the HCF affected in the outbreaks were included in the case numbers. Outbreaks were included regardless of the strength of evidence that could link FBO cases to a food vehicle.

We excluded descriptions of outbreaks that did not occur in a member country of the Organisation for Economic Co-operation and Development (OECD), community outbreaks, pre-2001 outbreaks, outbreaks that were unlikely foodborne (e.g. person-to-person transmission, contaminated equipment), due to water consumption, involving enteral/parenteral (powdered) formulae, outbreaks with only members of HCF personnel affected, and caused by histamine poisoning, nonoriginal studies (literature reviews).

First, we carried out a search on PubMed on the 26 April 2019 for publications from 2001 onwards. We used search terms, respecting available synonyms for the following categories: healthcare-associated, outbreak, and foodborne pathogens (Supplement S1).

In addition, we conducted a search for outbreak reports in the Outbreak Database, a worldwide database for healthcare-associated outbreaks (www.outbreakdatabase.com) [16]. This database is managed by the Institute for Hygiene and Environmental Medicine at the Charité, University Medicine Berlin, Germany. Currently it contains 3,682 outbreak reports published between
1956 and 2020 and provides information in different fields and categories, such as geographical setting, demographics of persons affected, pathogen, source, transmission and measures. We queried this database on 26 April 2019 for outbreaks published from 2001 onwards using the search term 'food'.

Finally, we hand-searched the reference lists of included literature for additional relevant titles. All references were managed in EndNote version $X_{7}$ (Thomson Reuters, New York, United States (US)).

Titles and abstracts were screened by the first author (IB), followed by a full text screening for eligibility (Figure).

\section{Surveillance data from Germany}

The German electronic surveillance system (SurvNet@ RKI) covers infectious diseases that are mandatorily notifiable according to Germany's Protection against Infection Act [17] that came into effect in 2001 and since 2012 a systematic national data collection for the notification of healthcare-associated infection outbreaks is in place [18]. We searched the surveillance system for HA-FBO using the selection criteria 'outbreaks' AND 'foodborne' AND 'healthcare facilities' OR 'nursing homes' notified between 2012 and 2018 in Germany. The search date was 11 September 2019. The FBO were categorised as 'strong-evidence' and 'weakevidence' according to the EFSA classification which 
is based on the strength of evidence for the association between illnesses and a suspected food vehicle in the FBO [19]. Information on likely food vehicles was extracted from the available data for 'strong-evidence' outbreaks only. For FBO that were classified as 'weakevidence' information on suspected food vehicles was not always available, or the association of illnesses and suspected food vehicles was considered as vague.

\section{European Union foodborne outbreak database} Since 2004, EFSA has been tasked with the EU-wide data collection on FBO [20]. The EU system for monitoring and collection of information on FBO is based on the Directive 2003/99/EC of the European Parliament and of the Council. The reporting of data on FBO including causative agents and incriminated foodstuffs by the EU countries is mandatory [21]. Data on strongevidence FBO during the years 2010-2018 in the setting 'hospital or medical care facilities' were publicly available as supplemental material complementing the published EU annual summary reports or available on the EFSA Knowledge Junction [22-30].

\section{Data extraction}

We extracted data into a Microsoft Excel template. The following data were systematically extracted: publication characteristics (author(s), publication year, journal), country, outbreak year, healthcare setting, causative agent, number of cases, deaths, patient age and sex distribution if available, suspected food vehicle, associated factors (inadequate time-temperature control, insufficient kitchen hygiene and food hygiene processing, carriers of pathogens among food handlers, consumption of high-risk food items), and microbiological or epidemiological evidence regarding the link between cases and suspected food vehicles (i.e. descriptive or analytical epidemiology, microbiological detection, product-tracing).

The HA-FBO data extracted from the literature review were combined with HA-FBO data from the German surveillance system and merged into one dataset. Data from the EU foodborne outbreak database were analysed separately.

\section{Data analyses}

We calculated total number of outbreaks by pathogen, the number of outbreaks cases (median and range) and the number of deaths stratified by healthcare setting, food vehicles and year of outbreak.

\section{Ethical statement}

Ethical approval was not applicable, as all data were based on published data and anonymously transmitted surveillance data.

\section{Results}

We retrieved a total of 1,133 entries from PubMed and from the Outbreak Database. Additionally, we identified 18 studies from reference lists screening (Figure).
In total 59 publications describing 57 HA-FBO fulfilled the selection criteria (Supplement S1, Table S1). All included publications were in English, except for two publications in German [31,32] and one in Spanish [33]. HA-FBO were reported from 16 OECD countries: Germany [31,32,34-42], US [43-55], UK [56-63], Spain [33,64-66], Japan [67-71], Austria [72-74], Australia [75,76], Canada [44,77,78], Denmark [79,80], France [81,82], Finland [83], Greece [84], Italy [85], Norway [86], the Netherlands $[36,87]$, Turkey [88] and included three multinational outbreaks $[36,44,56]$. The countries with the highest number of published HA-FBO were Germany (11/57), the US (11/57) and the UK (9/57). Between 2001 and 2018, there was no trend in time, except that no published HA-FBO was reported with outbreak onset in 2015, 2017 and 2018, most likely because of publication delay.

From the German surveillance data (2012-2018), 28 HA-FBO were identified. Of these, nine HA-FBO (32\%) had been classified as strong-evidenceFBO (Supplement S1, Table S1), four due to norovirus, two due to Listeria monocytogenes, two due to Salmonella and one due to Bacillus cereus. Nineteen HA-FBO had been classified as weak-evidence FBO (nine due to norovirus, six due to Salmonella, two due to Campylobacter jejuni, one due to Bacillus cereus and one due to Clostridium perfringens).

Of the combined 85 HA-FBO in total, 24 were caused by Salmonella, $22(26 \%)$ by norovirus and $19(22 \%)$ by L. monocytogenes (Table 1). One HA-FBO was caused by the parasitic pathogen Cyclospora cayetanensis [55], while another one was associated with the fungus Blastoschizomyces capitatus [66]. In total, 3,802 cases were associated with these outbreaks, and 90 deaths occurred (2.4\%). Specific details on each HA-FBO, including the type of evidence linking case-patients and suspected food vehicles are listed in the Supplement S1, Table S1.

\section{Case-patients}

A high number of case-patients per outbreak was observed in norovirus HA-FBO (median: 35 casepatients, range: 2-570), with one reported death. Salmonellosis HA-FBO included in median 29 casepatients per outbreak (range: 2-130) and altogether 11 deaths were attributed to these outbreaks. In contrast, listeriosis HA-FBO were typically characterised by a smaller number of case-patients per outbreak (median: 5, range: $2-48$ case-patients) but a higher number of deaths. In total 65 deaths (on a total of 90 fatalities; $72 \%$ ) were associated with listeriosis HA-FBO (median case fatality (CF) per outbreak: 33\%, range: 0-100). The four Escherichia coli HA-FBO $[54,70,71,78]$ had a high number of case-patients per outbreak (median: 77, range: 4-109), including eight deaths and a CF ranging from o to $4.7 \%$ (median: $2 \%$ ).

Specific information on the age of the outbreak cases was available for 55 of 85 (65\%) HA-FBO (Supplement 
$\mathrm{S}_{1}$, Table $\mathrm{S}_{1}$ ). The median age of the case-patients per HA-FBO was 65 years or older for 28 of 52 HA-FBO with available information. Three further HA-FBO reported a mean age of 65 years or older. In particular, the median age of the case-patients was $\geq 65$ years in eight of 13 $(62 \%)$ listeriosis HA-FBO with quantitative information on age available. Eight HA-FBO infants below 1 year of age were affected $([44,70,82]$, Supplement S1, Table S1). The proportion of female case-patients was $50 \%$ (59/117 outbreak cases) in 13 listeriosis HA-FBO, $51 \%$ ( $252 / 490$ outbreak cases) in 14 norovirus HA-FBO, and $59 \%$ (216/364 outbreak cases) in 12 salmonellosis HA-FBO. Personnel (medical and non-medical staff, food handlers etc) of HCF were mentioned among the case-patients in $27 / 61(43 \%) \mathrm{HA}-\mathrm{FBO}$.

\section{Settings}

In total, 39 of 85 HA-FBO occurred in hospitals, followed by 23 of 85 nursing homes, 13 of 85 multiple healthcare settings and 10 of 85 rehabilitation centres (Table 1 ). In particular, L. monocytogenes was responsible for 16 of 39 of the HA-FBO affected hospitals, whereas in nursing homes, nine of $23 \mathrm{HA}-\mathrm{FBO}$ were caused by Salmonella spp. In some HA-FBO occurring in hospital settings, several wards in the same hospital or even several hospitals were affected $[35,42,47,48,76]$. In some HA-FBO in the nursing home setting, the outbreak involved several nursing home sites $[37,71]$.

Food vehicles

Different food sources were associated with bacterial, viral infections, parasitic or fungal infections. Table 2 shows the top three food categories associated with listeriosis, salmonellosis and norovirus HA-FBO.

Information on the implicated food vehicle was missing or vague in 25 of $85 \mathrm{HA}-\mathrm{FBO}$, including 12 norovirus and nine salmonellosis HA-FBO. Overall the most frequently reported implicated food vehicles in HA-FBO were mixed foods $(16 / 60 ; 27 \%$ of HA-FBO, including seven listeriosis HA-FBO associated with sandwiches) and vegetables and fruits $(15 / 60 ; 25 \%$ of HA-FBOs). In particular, nine HA-FBO have vegetables as likely source of vehicle $([36,42,43,47,54,55,69,71]$, Supplem ent $\mathrm{S}_{1}$, Table $\mathrm{S}_{1}$ ) were associated with a large range of pathogens, whereas four of six HA-FBO associated with fruits were linked to frozen berries contaminated by norovirus $([40,79]$, Supplement S1, Table S1). 'Vegetables and fruits' were the food vehicles associated with the highest number of case-patients $(1,308 / 3,802$ case-patients; $35 \%)$. Furthermore, meat and meat products were associated with $10 / 60(17 \%)$ of the HA-FBO. However, the combination of all food vehicles of animal origin accounted for 22 of 60 (37\%) HA-FBO. These were mainly associated with $L$. monocytogenes (ready-sliced meat jelly [83], scalded sausage [41], spiced meat roll [80], delicatessen meat [77], milkshake/ice cream [48,51], Camembert cheese [86], and tuna salad [46]), and Salmonella spp. (including eggs $[45,56,63]$ and raw pork [37]).

\section{Antibiotic resistance}

In four HA-FBO details on antibiotic-resistant strains were provided. These comprised a HA-FBO caused by a carbapenemase-expressing (VIM-type) Citrobacter freundii with 76 colonisations in several wards of a university hospital [42], a S. Enteritidis outbreak (resistant to nalidixic acid, low level susceptibility to ciprofloxacin) associated with eggs [63], an ESBLproducing Klebsiella pneumoniae (SHV1 and CTX-M-15) outbreak (resistant to penicillin and third-generations cephalosporin) affecting patients with indwelling catheter, surgical infections and primary bacteraemia [65] and an ESBL-producing E. coli outbreak transmitted through donor breast milk in a neonatal intensive care unit [70].

\section{Preventable causes}

Associated factors that may have contributed to the respective outbreaks were described for 35 of 85 (41\%) HA-FBO. Inadequate time or temperature control during food preparation was reported for 16 of the $35(46 \%)$ HA-FBO associated with Salmonella [34$36,63,87]$, L. monocytogenes [57,59-62], C. perfringens [52,69], E. coli [70], C. jejuni [74], C. freundii [42]. In 10 of $35(29 \%)$ HA-FBO, food or ingredients that were considered risky for vulnerable populations in HCF were mentioned. These included raw pork products [37], deli-meat [77], (uncooked) frozen berries $[40,79]$, raw unpasteurised shell eggs [45,63], raw oysters [81], and bean sprouts [36]. Carriers among kitchen personnel or food handlers were reported for eight of 35 (23\%) HA-FBO, including outbreaks associated with Salmonella [32,38,43], norovirus [72] and $K$. pneumoniae [65]. Insufficient hygiene practices in processing raw foodstuff or inadequate cleaning of the kitchen, equipment or environment were reported in five HA-FBO, caused by Salmonella [38,84], L. monocytogenes [50,51] and K. pneumoniae [65]. In 29 HA-FBO (16 L. monocytogenes, seven Salmonella, three norovirus, one $B$. cereus, one E. coli and one Cyclospora cayetanensis $\mathrm{HA}-\mathrm{FBO}$ ), trace-back investigations linked the HA-FBO to caterer companies or suppliers. Traceback investigations were most frequently reported for listeriosis $[41,47,48,51,57-62,71,76,77,80,83,86]$, followed by salmonellosis HA-FBO $[31,34-36,56,63,75]$. In norovirus HA-FBO associated with frozen berries $[40,79]$, an incriminated batch or a company could be identified.

\section{Healthcare-associated foodborne outbreaks in the European Union foodborne outbreak database}

A total of 88 strong-evidence FBO and no waterborne outbreak were reported in hospitals or medical care facilities by 14 EU countries between 2010 and 2018 [22-30]. The majority of these outbreaks were notified by Poland $(33 / 88 ; 38 \%)$ and by France $(25 / 88 ; 28 \%)$. The top three pathogens causing these outbreaks were norovirus $(20 / 88 ; 23 \%)$, Salmonella $(12 / 88 ; 14 \%)$ and C. perfringens $(12 / 88 ; 14 \%)$. Listeriosis HA-FBO were less frequently reported $(8 / 88 ; 9 \%)$. From these 
eight strong-evidence listeriosis HA-FBO, 45 illnesses, including seven deaths (CF: 16\%) were reported. A single HA-FBO caused by Trichinella spiralis with four casepatients was reported by Poland. Distribution of FBO pathogens differed by reporting countries. For instance, 11 of 12 outbreaks due to $C$. perfringens were reported by France. Implicated food vehicles were mainly mixed foods $(25 / 88 ; 28 \%)$, meat and meat products $(24 / 88$; $27 \%)$ and fruits and vegetables (11/88; 13\%). From 14 HA-FBO reports $[35-37,39,40,42,56,61,62,73,80-83]$ that occurred in the EU between 2010 and 2018 we retrieved three matching records of Listeria outbreaks in the EU foodborne outbreak database $[61,62,83]$.

\section{Discussion}

The top three pathogens causing HA-FBO retrieved from the published reports and the German surveillance system were Salmonella, norovirus, and L. monocytogenes, whereas in the EFSA foodborne outbreak database, the top three pathogens causing HA-FBO consisted of norovirus, Salmonella and C. perfringens. In the current study, Listeria monocytogenes was responsible for the majority of the HA-FBO in the hospital setting and characterised by a high case fatality affecting mainly vulnerable patients with comorbidities and elderly patients. Listeriosis outbreaks were less frequently reported to EFSA's foodborne outbreak database compared with those included in the current study. In total, 4 of 85 (5\%) HA-FBO due to C. perfringens were included in this study. A few HA-FBO were caused by less common foodborne pathogens such as K. pneumoniae [65], C. freundii [42], Cyclospora cayetanesis [55] and B. capitatus [66] which highlights that such pathogens should not be neglected as HA-FBO. Strong-evidence FBO caused by Trichinella, Cryptospor idium, Giardia and Anisakis have been reported to EFSA in different settings between 2010 and 2018, but only one FBO caused by $T$. spiralis was reported in a hospital or medical care facility. Although Toxoplasma gondii is prevalent in humans and animals and reporting of foodborne toxoplasmosis disease outbreaks in humans is mandatory in the EU, no FBO caused by this parasite has been reported to EFSA since the start of the FBO reporting, in 2004 [2].

Four HA-FBO resulted in foodborne transmission of antibiotic-resistant strains which is especially relevant in a medical setting $[42,63,65,70]$. The vehicles were an egg delivery, pre-sliced vegetables, breast milk and in one instance the food item remained unclear. Contaminations were most likely in-house.

In several HA-FBO, several HCF, wards and multiple healthcare settings were affected $[76,31,35,36,42,44,47,48,68,77-80,83,87,89]$. Moreover, in several HA-FBO, there were outbreak cases in the community in addition to the outbreak cases in the HCF. This implies that different HCFs may have been served by the same kitchen, that caterers provided food to several healthcare institutions and to the community and that large food distribution chains play an important role in HA-FBO. This highlights the importance for food chain distribution analyses of HCFs in outbreak investigations to support laboratory and epidemiological investigations. Food suppliers or caterers for HCF should reinforce their companies' own checks to guarantee that no contaminated products enter HCF.

Although no retrieved Listeria HA-FBO occurred only in nursing homes, three long-term care facilities were affected as part of multiple settings $[77,80,83]$. Listeriosis HA-FBO are difficult to detect as only single but severe cases occur over a prolonged time. The foodborne aetiology of the bacteraemia is often not detected.

A major part of the HA-FBO was related to mixed food, fruits and vegetables and meat and meat products. The risk of ready-to-eat sandwiches (mixed food) for hospital patients has been highlighted in a listeriosis outbreak in 2019 in the UK [14]. The importance of mixed foods suggests the need for improved hygienic standards for food preparation processing and preparation of food in HCF and external companies delivering ready-to-eat (RTE) meals to HCF, especially RTE that did not receive a treatment to inactivate foodborne pathogens. With respect to HA-FBO caused by fruits and vegetables, frozen berries should be heat-treated before offered for consumption and berries that have not been heated should not be served to vulnerable or immunocompromised patients. Furthermore, fresh produce (e.g. mung bean sprouts [36], raw celery [47], raw spinach [54]) should be considered as a risk for vulnerable patients. Similar to the currents study, the top three HA-FBO reported to EFSA were associated with mixed foods, meat/meat products and vegetables/ fruits [22-30].

Some HCF might focus on nutritional risk in vulnerable patients or might be more concerned about diet composition and neglect the microbial food safety and respective guidelines [90]. A diet should therefore be selected that is suitably nutritious and palatable without using high-risk foods. Limited budgets of healthcare institutions may lead to minimising catering costs, which may have an impact on the quality of the food served. In Germany, hospitals spent on average 5.14 Euros on food products per patient per day in 2018 [91]. In Italy in 2016, the average expense for meals in public hospitals was 7.90 Euros per patient per day [92]. In a large proportion of the HA-FBO, both patients and nursing home residents, and staff members including healthcare workers and kitchen personnel were affected, which highlights the role of personnel (medical and non-medical staff, food handlers etc) of HCF in spreading outbreaks, e.g. through further secondary cases, and the disruptive impact on the management of the services of the HCF [3]. 
Food business operators should improve and constantly control all food production procedures based on the HACCP principles (Regulation (EC) No 852/2004, Hygiene Package) [93], especially when the catering is outsourced. Food safety in HCF should be ensured and supply chains strictly controlled [12]. In Germany, food safety recommendations for healthcare settings are available for the food safety sector [94,95], and the public health and hospital infection control sector [9698] but can be further elaborated to achieve awareness in practice in more HCF.

With HA-FBO mainly from Germany, the US, and the UK and mainly published in English, we suspect that there was a publication bias which may limit the overall body of evidence on HA-FBOs. We did not include a separate search in national public health journals in local languages, therefore we may have overlooked reports of HA-FBOs. In addition, there may be a lack of systematic surveillance of FBO in HCF as compared with other healthcare-associated infections. The identification of HA-FBO cases in HCF could be complicated among patients with comorbidities. The number of fatalities among patients with comorbidities may have been overestimated, because the foodborne infection may not have been causative for or contributed to the death.

Retrieved HA-FBO did not all provide details on age and sex of the outbreak-cases, settings and description of the cases among healthcare workers and other personal.

No overlaps were found between HA-FBO obtained from the literature review and those retrieved from the German surveillance system, either because these outbreaks were not categorised in a HCF setting, or because the outbreak was not reported in the surveillance system.

Comparisons of the HA-FBO from the current review with the EFSA data on strong-evidence $\mathrm{FBO}$ in hospitals or medical care facilities should be made with caution. The low degree of matching between HA-FBO from the literature and the EFSA database can partly be explained by the fact that from the latter only the 'hospital or medical care facility' setting was included, and non-matching HA-FBO from the literature may have been classified under different settings in the EFSA database, such as 'residential institution (nursing home or prison or boarding school)', 'disseminated cases', or 'multiple places of exposure'.

The fact that $C$. perfringens was the third most reported agent for strong-evidence FBO in setting hospital or medical care facility in the EFSA database may in major part be related to the MS> specific reporting. Noteworthy, the variable place of exposure is an optional data element. More generally, although the data reporting rules follow the same EFSA standard specifications, the surveillance activities of FBO are not fully harmonised across EU countries and differences in sensitivity and type of outbreaks under surveillance exist [99]. For this reason, the difference in the numbers and types of reported FBO, as well as in the causative agents and the type of outbreaks may not necessarily reflect the level of food safety in the countries.

\section{Conclusion}

HCF should ensure that foods, especially ready-to-eat foods offered to patients and nursing home residents are free of pathogens and that high-risk foods are avoided, by implementing food safety measures and strictly controlling food supply chains.

Despite regulations to govern food safety and existing guidelines on food safety, there is still a need to raise awareness including regular food safety training programmes for HCF staff and to enforce adherence to safe food policies, especially regarding food for highly vulnerable or immunocompromised patients. Additionally, in-house contamination of food during preparation should be avoided. Surveillance of healthcare-associated infections should be integrated with surveillance of foodborne diseases to improve detection of HA-FBO. In addition, close interdisciplinary collaboration and exchange of information between hospital infection control, food safety, and public health authorities is necessary.

More studies are necessary to appraise the burden of HA-FBO and more detailed descriptions of HA-FBO including the role of personnel (medical and non-medical staff, food handlers etc) of HCF should be documented in reports and in surveillance data.

\section{*Erratum}

The following corrections were made to the title: 'OEDC' was replaced with 'OECD'. The same correction was undertaken for the Table 1 title and the respective table note and for the Table 2 title. The errors were corrected on 21 October 2021. We apologise for any inconvenience this may have caused.

\section{Acknowledgements}

This work was done as part of the NOVA project under the One Health EJP, a European Union's Horizon 2020 research and innovation programme under Grant Agreement No 773830. We thank Thomas Harder (Robert Koch Institute) and Gaia Scavia (Istituto Superiore di Sanità) for critically reviewing the manuscript.

\section{Disclaimer}

Yves Van der Stede and Frank Boelaert are currently employed with the European Food Safety Authority (EFSA) respectively in its Animal Health and Welfare and Plant Health (ALPHA) Unit that provides scientific and administrative support to EFSA's scientific activities in the area of Animal Health and Welfare and in its Biological Hazards and Contaminants Unit that provides scientific and administrative support 
to the Panel on Biological Hazards (BIOHAZ), the Panel on Contaminants in the Food Chain (CONTAM) and to EFSA's scientific activities in the area of analyses of data on zoonoses, antimicrobial resistance and foodborne outbreaks across the European Union. The positions and opinions presented in this article are those of the authors alone and are not in tended to represent the views or scientific works of EFSA. To know about the views or scientific outputs of EFSA, please consult its website under http://www.efsa.europa.eu.

\section{Conflict of interest}

None declared.

\section{Authors' contributions}

Idesbald Boone, Sebastian Haller and Hendrik Wilking conceived the study idea. Idesbald Boone carried out the PubMed and the Outbreak Database search and searched the German national surveillance system, performed data extraction and analysis and drafted the manuscript. Bettina Rosner performed the search and extracted data from the surveillance system and critically reviewed the manuscript. Sebastian Haller and Hendrik Wilking contributed to the conceptualisation and methodology, and critically reviewed the manuscript. Frank Boelaert (European Food Safety Authority, Parma, Italy) and Yves Van der Stede (European Food Safety Authority, Parma, Italy) extracted data from the EU Foodborne Outbreak database and critically reviewed the manuscript. Raskit Lachman, Michele Luca D’Errico, Luigi lannetti, Steen Ethelberg, Tim Eckmanns and Klaus Stark critically reviewed and edited the manuscript.

\section{References}

1. World Health Organization (WHO). WHO estimates of the global burden of foodborne diseases: foodborne disease burden epidemiology reference group 2007-2015. Geneva: WHO; 2015. Available from: https://apps.who.int/iris/bitstream/ handle/10665/199350/9789241565165_eng.pdf?sequence $=1$

2. European Food Safety Authority and European Centre for Disease Prevention and Control (EFSA and ECDC). The European Union One Health 2018 Zoonoses Report. EFSA J. 2019;17(12):e05926. https://doi.org/10.2903/j.efsa.2019.5926 PMID: 32626211

3. Lund BM, O'Brien SJ. The occurrence and prevention of foodborne disease in vulnerable people. Foodborne Pathog Dis. 2011;8(9):961-73. https://doi.org/10.1089/fpd.2011.0860 PMID: 21561383

4. Eurostat. Population structure and ageing 2019. Luxembourg: Eurostat; 2019. Available from: https:// ec.europa.eu/eurostat/statisticsexplained/index. php?title=Population_structure_and_ageing

5. Lund BM, O'Brien SJ. Microbiological safety of food in hospitals and other healthcare settings. J Hosp Infect. 2009;73(2):109-20. https://doi.org/10.1016/j.jhin.2009.05.017 PMID: 19732991

6. Lee MB, Greig JD. A review of nosocomial Salmonella outbreaks: infection control interventions found effective. Public Health. 2013;127(3):199-206. https://doi.org/10.1016/j. puhe.2012.12.013 PMID: 23433804

7. Little CL, Amar CF, Awofisayo A, Grant KA. Hospital-acquired listeriosis associated with sandwiches in the UK: a cause for concern. J Hosp Infect. 2012;82(1):13-8. https://doi. org/10.1016/j.jhin.2012.06.011 PMID: 22868087

8. Lopez-Valladares G, Danielsson-Tham ML, Tham W. Implicated food products for Listeriosis and changes in serovars of listeria monocytogenes affecting humans in recent decades. Foodborne Pathog Dis. 2018;15(7):387-97. https://doi. org/10.1089/fpd.2017.2419 PMID: 29958028

9. Silk BJ, McCoy MH, Iwamoto M, Griffin PM. Foodborne listeriosis acquired in hospitals. Clin Infect Dis. 2014;59(4):532-40. https://doi.org/10.1093/cid/ciu365 PMID: 24846635

10. Petrignani M, van Beek J, Borsboom G, Richardus JH, Koopmans M. Norovirus introduction routes into nursing homes and risk factors for spread: a systematic review and meta-analysis of observational studies. J Hosp Infect. 2015;89(3):163-78. https://doi.org/10.1016/j.jhin.2014.11.015 PMID: 25601744

11. Greig JD, Lee MB. A review of nosocomial norovirus outbreaks: infection control interventions found effective. Epidemiol Infect. 2012;140(7):1151-6o. https://doi.org/10.1017/ So950268811002731 PMID: 22217255

12. Lund BM. Provision of microbiologically safe food for vulnerable people in hospitals, care homes and in the community. Food Control. 2019;96:535-47. https://doi. org/10.1016/j.foodcont.2018.09.032

13. Lachmann R, Halbedel S, Adler M, Becker N, Allerberger F, Holzer A, et al. Nationwide outbreak of invasive listeriosis associated with consumption of meat products in health care facilities, Germany, 2014-2019. Clin Microbiol Infect. 2020;7:S1198-743X(20)30572-3. PMID:32979571

14. Public Health England (PHE). Investigation into an outbreak of Listeria monocytogenes infections associated with hospitalprovided prepared sandwiches, UK, May to July 2019. London: PHE; 2020. Available from: https://assets.publishing.service. gov.uk/government/uploads/system/uploads/attachment data/file/937907/2019-05-Listeria-CC8-Outbreak-Report.p̄ff

15. Organisation for Economic Cooperation and Development (OECD). List of OECD member countries - Ratification of the Convention on the OECD. Paris: OECD. [Accessed: 17 Oct 2021]. Available from: https://www.oecd.org/about/document/listoecd-member-countries.htm

16. Vonberg RP, Weitzel-Kage D, Behnke M, Gastmeier P. Worldwide Outbreak Database: the largest collection of nosocomial outbreaks. Infection. 2011;39(1):29-34. https:// doi.org/10.1007/S15010-010-0064-6 PMID: 21153042

17. Bundesministerium der Justiz und für Verbraucherschutz (Federal Ministry of Justice and Consumer Protection). Gesetz zur Verhütung und Bekämpfung von Infektionskrankheiten beim Menschen. [Law for the Prevention and Control of Infectious Diseases in Humans]. Berlin: Federal Ministry of Justice and Consumer Protection. [Accessed: 7 Oct 2021]. German. Available from: https://www.gesetze-im-internet.de/ ifsg/

18. Haller S, Eckmanns T, Benzler J, Tolksdorf K, Claus H, Gilsdorf $A$, et al. Results from the first 12 months of the national surveillance of healthcare associated outbreaks in Germany, 2011/2012. PLoS One. 2014;9(5):e98100. https://doi. org/10.1371/journal.pone.0098100 PMID: 24875674

19. European Food Safety Authority (EFSA). Update of the technical specifications for harmonised reporting of food-borne outbreaks through the European Union reporting system in accordance with Directive 2003/99/EC. EFSA Journal 2014; 12((3):3598). https://doi.org/10.2903/j.efsa.2014.3598

20. Boelaert F, Amore G, Van der Stede Y, Hugas M. EU-wide monitoring of biological hazards along the food chain: achievements, challenges and EFSA vision for the future. Curr Opin Food Sci. 2016;12:52-62. https://doi.org/10.1016/j. cofs.2016.08.004

21. European Union. Council Directive 2003/99/EC of the European Parliament and of the Council of 17 th of November 2003 on the monitoring of zoonoses and zoonotic agents amending Council Decision 90/424/EEC and repealing Council Directive 92/117/ EEC. Official Journal 2003; L325/31.

22. European Food Safety Authority and European Centre for Disease Prevention and Control (EFSA and ECDC). The European Union Summary Report on Trends and Sources of Zoonoses, Zoonotic Agents and Food-borne Outbreaks in 2010. EFSA J. 2012;10(3):2597. https://doi.org/10.2903/j.efsa.2012.2597

23. European Food Safety Authority and European Centre for Disease Prevention and Control (EFSA and ECDC). The European Union Summary Report on Trends and Sources of Zoonoses, Zoonotic Agents and Food-borne Outbreaks in 2011. EFSA J. 2013;11(4):3129. https://doi.org/10.2903/j.efsa.2013.3129

24. European Food Safety Authority and European Centre for Disease Prevention and Control (EFSA and ECDC). The European Union Summary Report on Trends and Sources of Zoonoses, Zoonotic Agents and Food-borne Outbreaks in 2012. EFSA J. 2014;12(2):3547. https://doi.org/10.2903/j.efsa.2014.3547

25. European Food Safety Authority and European Centre for Disease Prevention and Control (EFSA and ECDC). The European Union Summary Report on Trends and Sources of Zoonoses, Zoonotic Agents and Food-borne Outbreaks in 2013. EFSA J. 2015;13(1):3991. https://doi.org/10.2903/j.efsa.2015.3991

26. European Food Safety Authority and European Centre for Disease Prevention and Control (EFSA and ECDC). The European Union summary report on trends and sources of zoonoses, zoonotic agents and food-borne outbreaks in 2014. EFSA J. 2015;13(12):4329. https://doi.org/10.2903/j.efsa.2015.4329 
27. European Food Safety Authority and European Centre for Disease Prevention and Control (EFSA and ECDC). The European Union summary report on trends and sources of zoonoses, zoonotic agents and food-borne outbreaks in 2015. EFSA J. 2016;14(12):4634. https://doi.org/10.2903/j.efsa.2016.4634

28. European Food Safety Authority \& European Centre for Disease Prevention and Control. Tables and figures complementing the European Union One Health 2018 Zoonoses Report [Data set]. Zenodo. 2019. https://doi.org/http://doi.org/10.5281/ zenodo.3527706

29. European Food Safety Authority (EFSA). Tables, Figures and Country Datasets complementing the European Union Summary Report on Zoonoses and Food-borne Outbreaks 2016 [Data set]. Zenodo. 2017. http://doi.org/10.5281/ zenodo.1475841

30. European Food Safety Authority. Tables, Figures and Country Datasets complementing the European Union Summary Report on Zoonoses and Food-borne Outbreaks 2017 [Data set]. Zenodo. 2018. http://doi.org/10.5281/zenodo.1475841

31. Heissenhuber A, Hautmann W, Arenz S, Kugler R, Kleih W, Ludwig S, et al. Gehäuftes Auftreten von Erkrankungen mit Salmonella Enteritidis in Krankenhäusern und Altenheimen im Landkreis Oberallgäu (Bayern) im Juli 2004. [Accumulated occurrence of illnesses with Salmonella enteritidis in hospitals and nursing homes in the district Oberallgaeu, Bavaria, in July 2004]. Gesundheitswesen. 2005;67(12):845-52.German. https://doi.org/10.1055/s-2005-858898 PMID:16379046

32. Jansen A, Hiller P, Desai S, Feier B, Habermann F, Baumann A, et al. Protrahiert verlaufender nosokomialer Ausbruch von Salmonella Enteritidis LT 8/7. [Protracted nosocomial outbreak of Salmonella Enteritidis LT 8/7]. Z Gastroenterol. 2008;46(11):1270-4. German. https://doi. org/10.1055/s-2008-1027543 PMID:19012198

33. Almagro Nievas D, Conti Cuesta F, Espínola García E, Morcillo Ródenas C, Núñez Sevilla C, Linares Torres J, et al. Brote de gastroenteritis por virus Norwalk en una residencia de ancianos de Granada. [Outbreak of gastroenteritis caused by Norwalk virus at a senior citizens assisted living facility in Granada, Spain]. Rev Esp Salud Publica. 2003;77(2):283-91. Spanish. https://doi.org/10.1590/S1135-57272003000200011 PMID:12728663

34. Frank C, Buchholz U, Maass M, Schröder A, Bracht KH, Domke PG, et al. Protracted outbreak of S. Enteritidis PT 21C in a large Hamburg nursing home. BMC Public Health. 2007;7(1):243. https://doi.org/10.1186/1471-2458-7-243 PMID: 17854497

35. Poetter C, Kunstmann G, Peter D, Mattner F. Containment of a cheesecake-associated outbreak of salmonellosis in 3 different hospitals, detected by continuous microbiologic surveillance. Am J Infect Control. 2014;42(7):816-7. https://doi. org/10.1016/j.ajic.2014.03.013 PMID: 24825536

36. Bayer C, Bernard H, Prager R, Rabsch W, Hiller P, Malorny B, et al. An outbreak of Salmonella Newport associated with mung bean sprouts in Germany and the Netherlands, October to November 2011. Euro Surveill. 2014;19(1):20665. https://doi. org/10.2807/1560-7917.ES2014.19.1.20665 PMID: 24434173

37. Schielke A, Rabsch W, Prager R, Simon S, Fruth A, Helling $\mathrm{R}$, et al. Two consecutive large outbreaks of Salmonella Muenchen linked to pig farming in Germany, 2013 to 2014: Is something missing in our regulatory framework? Euro Surveill. 2017;22(18):30528. https://doi.org/10.2807/1560-7917. ES.2017.22.18.30528 PMID: 28494842

38. Miller T, Brockmann S, Spackova M, Wetzig J, Frank C, Pfeifer $Y$, et al. Recurrent outbreaks caused by the same Salmonella enterica serovar Infantis clone in a German rehabilitation oncology clinic from 2002 to 2009. J Hosp Infect. 2018;100(4):e233-8. https://doi.org/10.1016/j. jhin.2018.03.035 PMID: 29614246

39. Hoffmann D, Mauroy A, Seebach J, Simon V, Wantia N, Protzer U. New norovirus classified as a recombinant GII.g/ Gll.1 causes an extended foodborne outbreak at a university hospital in Munich. J Clin Virol. 2013;58(1):24-30. https://doi. org/10.1016/j.jcv.2013.06.018 PMID: 23849648

40. Bernard H, Faber M, Wilking H, Haller S, Höhle M, Schielke A, et al. Large multistate outbreak of norovirus gastroenteritis associated with frozen strawberries, Germany, 2012. Euro Surveill. 2014;19(8):20719. https://doi.org/10.2807/1560-7917. ES2014.19.8.20719 PMID: 24602278

41. Winter $\mathrm{CH}$, Brockmann SO, Sonnentag SR, Schaupp T, Prager $\mathrm{R}$, Hof $\mathrm{H}$, et al. Prolonged hospital and community-based listeriosis outbreak caused by ready-to-eat scalded sausages. J Hosp Infect. 2009;73(2):121-8. https://doi.org/10.1016/j. jhin.2009.06.011 PMID: 19716628

42. Pletz MW, Wollny A, Dobermann UH, Rödel J, Neubauer S, Stein C, et al. A nosocomial foodborne outbreak of a VIM Carbapenemase-expressing Citrobacter freundii. Clin Infect Dis. 2018;67(1):58-64. https://doi.org/10.1093/cid/ciy034 PMID: 29346622
43. Elward A, Grim A, Schroeder P, Kieffer P, Sellenriek P, Ferrett R, et al. Outbreak of Salmonella javiana infection at a children's hospital. Infect Control Hosp Epidemiol. 2006;27(6):586-92. https://doi.org/10.1086/506483 PMID: 16755478

44. Centers for Disease Control and Prevention (CDC). Salmonella Oranienburg infections associated with fruit salad served in health-care facilities--northeastern United States and Canada, 2006. MMWR Morb Mortal Wkly Rep. 2007;56(39):1025-8. PMID: 17914330

45. Styles T, Phan Q, Rabatsky-Ehr T, Applewhite C, Sosa L, Cartter M. Salmonella enterica serotype enteritidis outbreak at a long-term care facility, Connecticut, 2012. Conn Med. 2013;77(10):587-90. PMID: 24367841

46. Cokes C, France AM, Reddy V, Hanson H, Lee L, Kornstein L, et al. Serving high-risk foods in a high-risk setting: survey of hospital food service practices after an outbreak of listeriosis in a hospital. Infect Control Hosp Epidemiol. 2011;32(4):380-6. https://doi.org/10.1086/658943 PMID: 21460490

47. Gaul LK, Farag NH, Shim T, Kingsley MA, Silk BJ, Hyytia-Trees E. Hospital-acquired listeriosis outbreak caused by contaminated diced celery--Texas, 2010. Clin Infect Dis. 2013;56(1):20-6. https://doi.org/10.1093/cid/cis817 PMID: 22997210

48. Centers for Disease Control and Prevention (CDC). Multistate outbreak of listeriosis linked to Blue Bell creameries products (Final Update). 10 Jun 2015. Available from: https://www.cdc. gov/listeria/outbreaks/ice-cream-03-15/index.html

49. Li Z, Pérez-Osorio A, Wang Y, Eckmann K, Glover WA, Allard $\mathrm{MW}$, et al. Whole genome sequencing analyses of Listeria monocytogenes that persisted in a milkshake machine for a year and caused illnesses in Washington State. BMC Microbiol. 2017;17(1):134. https://doi.org/10.1186/s12866-017-1043-1 PMID: 28619007

50. Mazengia E, Kawakami V, Rietberg K, Kay M, Wyman P, Skilton C, et al. Hospital-acquired listeriosis linked to a persistently contaminated milkshake machine. Epidemiol Infect. 2017;145(5):857-63. https://doi.org/10.1017/ So950268816003198 PMID: 28065212

51. Rietberg K, Lloyd J, Melius B, Wyman P, Treadwell R, Olson G, et al. Outbreak of Listeria monocytogenes infections linked to a pasteurized ice cream product served to hospitalized patients. Epidemiol Infect. 2016;144(13):2728-31. https://doi. org/10.1017/S0950268815003039 PMID: 27586030

52. Bos J, Smithee L, McClane B, Distefano RF, Uzal F, Songer $J$, et al. Fatal necrotizing colitis following a foodborne outbreak of enterotoxigenic Clostridium perfringens type $A$ infection. Clin Infect Dis. 2005;40(10):e78-83. https://doi. org/10.1086/429829 PMID: 15844055

53. Centers for Disease Control and Prevention (CDC). Fatal foodborne Clostridium perfringens illness at a state psychiatric hospital--Louisiana, 2010. MMWR Morb Mortal Wkly Rep. 2012;61(32):605-8. PMID: 22895383

54. Reiss G, Kunz P, Koin D, Keeffe EB. Escherichia coli $\mathrm{O}_{157}: \mathrm{H}_{7}$ infection in nursing homes: review of literature and report of recent outbreak. J Am Geriatr Soc. 2006;54(4):680-4. https:// doi.org/10.1111/j.1532-5415.2006.00682.x PMID: 16686882

55. Centers for Disease Control and Prevention (CDC). Outbreak of cyclosporiasis associated with snow peas--Pennsylvania, 2004. MMWR Morb Mortal Wkly Rep. 2004;53(37):876-8. PMID: 15385921

56. Inns T, Lane C, Peters T, Dallman T, Chatt C, McFarland N, et al. A multi-country Salmonella Enteritidis phage type $14 \mathrm{~b}$ outbreak associated with eggs from a German producer: "near real-time' application of whole genome sequencing and food chain investigations, United Kingdom, May to September 2014. Euro Surveill. 2015;20(16):21098. https://doi. org/10.2807/1560-7917.ES2015.20.16.21098 PMID: 25953273

57. Shetty A, McLauchlin J, Grant K, O’Brien D, Howard T, Davies EM. Outbreak of Listeria monocytogenes in an oncology unit associated with sandwiches consumed in hospital. Hosp Infect. 2009;72(4):332-6. https://doi.org/10.1016/j. jhin.2009.01.012 PMID: 19278752

58. Dawson SJ, Evans MR, Willby D, Bardwell J, Chamberlain $\mathrm{N}$, Lewis DA. Listeria outbreak associated with sandwich consumption from a hospital retail shop, United Kingdom. Euro Surveill. 2006;11(6):89-91. https://doi.org/10.2807/ esm.11.06.00632-en PMID: 16801694

59. Public Health England (PHE). Human listeriosis linked to hospital sandwiches: implications for procurement and storage. Health Protection Report 2(35). 29 August 2008 news. London: PHE; 2008. Available from: https://webarchive. nationalarchives.gov.uk/20140714101922/http://www.hpa.org. uk/hpr/archives/2008/news3508.htm

6o. Public Health Agency Northern Ireland (HSC). The report of the Outbreak Control Team of the investigation of an outbreak of listeriosis in the Belfast Health and Social Care Trust during May to November 2008. Belfast: HSC: 2009. Available from: 
https://www.publichealth.hscni.net/sites/default/files/ ListeriaReport.pdf

61. Little CL, Gormley F, Mook P, Gillespie I, Foster K, Harris J, et al. Outbreaks of infection associated with ready-to-eat foods. London: Food Standards Agency; 2011. Available from: https:// acmsf.food.gov.uk/sites/default/files/mnt/drupal_data/ sources/files/multimedia/pdfs/committee/acm1014hpa.pdf.

62. Coetzee N, Laza-Stanca V, Orendi JM, Harvey S, Elviss NC, Grant KA. A cluster of Listeria monocytogenes infections in hospitalised adults, Midlands, England, February 2011. Euro Surveill. 2011;16(20):19869. https://doi.org/10.2807/ ese.16.20.19869-en PMID: 21616050

63. Public Health Laboratory Services. Salmonella Enteritidis outbreak in a London hospital - update. Commun Dis Rep CDR Wkly. 2003;13(8). Available from: https://webarchive. nationalarchives.gov.uk/20121102165301/http://www.hpa.org. uk/cdr/archives/back_issues.htm

64. Eriksen HM, Guerin PJ, Nygård K, Hjertqvist M, de Jong B, Rose $A M$, et al. Gastro-enteritis outbreak among Nordic patients with psoriasis in a health centre in Gran Canaria, Spain: a cohort study. BMC Infect Dis. 2004;4(1):45. https://doi. org/10.1186/1471-2334-4-45 PMID: 15511300

65. Calbo E, Freixas N, Xercavins M, Riera M, Nicolás C, Monistro 0 , et al. Foodborne nosocomial outbreak of SHV1 and CTXM-15-producing Klebsiella pneumoniae: epidemiology and control. Clin Infect Dis. 2011;52(6):743-9. https://doi. org/10.1093/cid/ciq238 PMID: 21367727

66. Gurgui M, Sanchez F, March F, Lopez-Contreras J, Martino R, Cotura A, et al. Nosocomial outbreak of Blastoschizomyces capitatus associated with contaminated milk in a haematological unit. J Hosp Infect. 2011;78(4):274-8. https:// doi.org/10.1016/j.jhin.2011.01.027 PMID: 21658800

67. Hamada K, Tsuji H. Salmonella Brandenburg and S. Corvallis involved in a food poisoning outbreak in a hospital in Hyogo Prefecture. Jpn J Infect Dis. 2001;54(5):195-6. PMID: 11754160

68. Ohwaki K, Nagashima H, Aoki M, Aoki H, Yano E. A foodborne norovirus outbreak at a hospital and an attached long-term care facility. Jpn J Infect Dis. 2009;62(6):450-4. PMID: 19934537

69. Tanaka D, Isobe J, Hosorogi S, Kimata K, Shimizu M, Katori $\mathrm{K}$, et al. An outbreak of food-borne gastroenteritis caused by Clostridium perfringens carrying the cpe gene on a plasmid. Jpn J Infect Dis. 2003;56(3):137-9. PMID: 12944687

70. Nakamura K, Kaneko M, Abe Y, Yamamoto N, Mori H, Yoshida A, et al. Outbreak of extended-spectrum $\beta$-lactamase-producing Escherichia coli transmitted through breast milk sharing in a neonatal intensive care unit. J Hosp Infect. 2016;92(1):42-6. https://doi.org/10.1016/j.jhin.2015.05.002 PMID: 26238662

71. Tabuchi A, Wakui T, Yahata Y, Yano K, Azuma K, Yamagishi $\mathrm{T}$, et al. A large outbreak of enterohaemorrhagic Escherichia coli 0157 , caused by low-salt pickled Napa cabbage in nursing homes, Japan, 2012. Western Pac Surveill Response J. 2015;6(2):7-11. https://doi.org/10.5365/wpsar.2014·5.1.012 PMID: 26306209

72. Schmid D, Kuo HW, Hell M, Kasper S, Lederer I, Mikula C, et al. Foodborne gastroenteritis outbreak in an Austrian healthcare facility caused by asymptomatic, norovirus-excreting kitchen staff. J Hosp Infect. 2011;77(3):237-41. https://doi. org/10.1016/j.jhin.2010.11.015 PMID: 21272956

73. Schmid D, Rademacher C, Kanitz EE, Frenzel E, Simons $\mathrm{E}$, Allerberger $\mathrm{F}$, et al. Elucidation of enterotoxigenic Bacillus cereus outbreaks in Austria by complementary epidemiological and microbiological investigations, 2013. Int J Food Microbiol. 2016;232:80-6. https://doi.org/10.1016/j. ijfoodmicro.2016.05.011 PMID: 27257745

74. Jelovcan S, Schmid D, Lederer I, Hell M, Rehberger K, Arnhold D, et al. Cluster of nosocomial campylobacteriosis, Austria 2006. J Hosp Infect. 2008;69(1):97-8. https://doi. org/10.1016/j.jhin.2008.01.010 PMID: 18329135

75. Tribe IG, Cowell D, Cameron P, Cameron S. An outbreak of Salmonella typhimurium phage type 135 infection linked to the consumption of raw shell eggs in an aged care facility. Commun Dis Intell Q Rep. 2002;26(1):38-9. PMID: 11950200

76. Najjar Z, Gupta L, Sintchenko V, Shadbolt C, Wang Q, Bansal N. Listeriosis cluster in Sydney linked to hospital food. Med J Aust. 2015;202(8):448-9. https://doi.org/10.5694/ mja14.00913 PMID: 25929511

77. Currie A, Farber JM, Nadon C, Sharma D, Whitfield Y, Gaulin C, et al. Multi-province listeriosis outbreak linked to contaminated deli meat consumed primarily in institutional settings, Canada, 2008. Foodborne Pathog Dis. 2015;12(8):645 52. https://doi.org/10.1089/fpd.2015.1939 PMID: 26258258

78. Bolduc D, Srour LF, Sweet L, Neatby A, Galanis E, Isaacs S, et al. Severe outbreak of Escherichia coli $\mathrm{O}_{157: \mathrm{H}_{7}}$ in health care institutions in Charlottetown, Prince Edward Island, fall, 2002. Can Commun Dis Rep. 2004;30(9):81-8. PMID: 15132397
79. Falkenhorst G, Krusell L, Lisby M, Madsen SB, Böttiger $B$, Mølbak K. Imported frozen raspberries cause a series of norovirus outbreaks in Denmark, 2005. Euro Surveill. 2005;10(9):E050922.2. https://doi.org/10.2807/ esw.10.38.02795-en PMID: 16788235

80. Kvistholm Jensen A, Nielsen EM, Björkman JT, Jensen T, Müller L, Persson S, et al. Whole-genome sequencing used to investigate a nationwide outbreak of listeriosis caused by ready-to-eat delicatessen meat, Denmark, 2014. Clin Infect Dis. 2016;63(1):64-70. https://doi.org/10.1093/cid/ciw192 PMID: 27025820

81. Loury P, Le Guyader FS, Le Saux JC, Ambert-Balay K, Parrot $\mathrm{P}$, Hubert $\mathrm{B}$. A norovirus oyster-related outbreak in a nursing home in France, January 2012. Epidemiol Infect. 2015;143(12):2486-93. https://doi.org/10.1017/ So950268814003628 PMID: 25567093

82. Decousser JW, Ramarao N, Duport C, Dorval M, BourgeoisNicolaos N, Guinebretière $\mathrm{MH}$, et al. Bacillus cereus and severe intestinal infections in preterm neonates: Putative role of pooled breast milk. Am J Infect Control. 2013;41(10):918-21. https://doi.org/10.1016/j.ajic.2013.01.043 PMID: 23769834

83. Jacks A, Pihlajasaari A, Vahe M, Myntti A, Kaukoranta SS, Elomaa N, et al. Outbreak of hospital-acquired gastroenteritis and invasive infection caused by Listeria monocytogenes, Finland, 2012. Epidemiol Infect. 2016;144(13):2732-42. https:// doi.org/10.1017/So950268815002563 PMID: 26493730

84. Gikas A, Kritsotakis El, Maraki S, Roumbelaki M, Babalis D, Scoulica E, et al. A nosocomial, foodborne outbreak of Salmonella Enterica serovar Enteritidis in a university hospital in Greece: the importance of establishing HACCP systems in hospital catering. J Hosp Infect. 2007;66(2):194-6. https://doi. org/10.1016/j.jhin.2007.03.001 PMID: 17482719

85. Medici MC, Morelli A, Arcangeletti MC, Calderaro A, De Conto $\mathrm{F}$, Martinelli $\mathrm{M}$, et al. An outbreak of norovirus infection in an Italian residential-care facility for the elderly. Clin Microbiol Infect. 2009;15(1):97-100. https://doi.org/10.1111/j.14690691.2008.02117.x PMID: 19220341

86. Johnsen BO, Lingaas E, Torfoss D, Strøm EH, Nordøy I. A large outbreak of Listeria monocytogenes infection with short incubation period in a tertiary care hospital. J Infect. 2010;61(6):465-70. https://doi.org/10.1016/j.jinf.2010.08.007 PMID: 20813130

87. Bruins MJ, Fernandes TM, Ruijs GJ, Wolfhagen MJ, van Rijnvan Berkel JM, Schenk BE, et al. Detection of a nosocomial outbreak of salmonellosis may be delayed by application of a protocol for rejection of stool cultures. J Hosp Infect. 2003;54(2):93-8. https://doi.org/10.1016/S01956701(03)00125-7 PMID: 12818580

88. Ertugrul BM, Erol N, Emek M, Ozturk B, Saylak OM, Cetin K, et al. Food-borne tonsillopharyngitis outbreak in a hospital cafeteria. Infection. 2012;40(1):49-55. https://doi.org/10.1007/ S15010-011-0166-9 PMID: 21826437

89. Schmid D, Lederer I, Pichler AM, Berghold C, Schreier E, Allerberger F. Norovirus-Ausbruch in einem Altenheim und Krankenhaus in Österreich. [An outbreak of Norovirus infection affecting an Austrian nursing home and a hospital]. Wien Klin Wochenschr. 2005;117(23-24):802-8. German. https://doi. org/10.1007/s00508-005-0473-1 PMID:16437316

90. Ministero della Salute (Italian Ministry of Health). Linee di indirizzo nazionale per la ristorazione ospedaliera assistenziale. [National guidelines for food catering in hospitals and care facilities]. Rome: Ministero della Salute; 2012. [Accessed: 29 Mar 2020]. Italian. Available from: http:// www.salute.gov.it/imgs/C_17_pubblicazioni_1435_allegato.pdf

91. Blum K, Lehmann E. Trends in der Krankenhausküche. [Trends in the hospital kitchen]. Das Krankenhaus. 2020; 3:241-244. [Accessed: 11 Feb 2021]. German. Available from: https://www. kup-consult.de/wp-content/uploads/2020/05/Trends-in-derKrankenhausku\%CC\%88che-Das-Krankenhaus-03-20.pdf

92. National Italian Authority against corruption (ANAC). Efficienza dei contratti pubblici e sviluppo di indicatori di rischio corruttivo - gennaio 2018. [Efficiency of public contracts and development of corruption risk indicators]. Rome: ANAC. [Accessed: 29 Mar 2020]. Italian. Available from: https://www.anticorruzione.it/ documents/91439/171945/Efficienza+dei+contratti+pu bblici+e+sviluppo+di+indicatori+di+rischio+corruttivo. pdf/54fcab35-54bo-35d7-88fa-5ace3249fbcf?t=1583849599647

93. European Parliament and Council. Regulation (EC) no 852/2004 of the European Parliament and of the Council of 29 April 2004 on the hygiene of foodstuffs. Official Journal of the European Union. Luxembourg: Publication Office of the European Union. 30.04.2014:L 139. Available from: https://eur-lex.europa.eu/ eli/reg/2004/852/oj/eng

94. Federal Institute for Risk Assessment (BfR). Safe food. Especially vulnerable groups in communal facilities. Berlin: BfR. [Accessed: 7 Oct 2021]. Available from: https://www.bfr. 
bund.de/cm/364/safe-food-especially-vulnerable-groups-incommunity-institutions.pdf

95. Federal Institute for Risk Assessment (BfR). Mögliche gesundheitliche Risiken durch kontaminierte Lebensmittel in Krankenhausküchen können durch geeignete Maßnahmen minimiert werden. [Possible health risks from contaminated food in hospital kitchens can be minimized by taking suitable measures]. Berlin: BfR; 2016. German. Available from: https:// www.bfr.bund.de/cm/343/moegliche-gesundheitliche-risikendurch-kontaminierte-lebensmittel-in-krankenhauskuechen-

koennen-durch-geeignete-massnahmen-minimiert-werden.pdf

96. German Society of Hospital Hygiene. Hygieneanforderungen beim Umgang mit Lebensmitteln in Krankenhäusern, Pflegeund Rehabilitationseinrichtungen und neuen Wohnformen. [Hygiene requirements when handling food in hospitals, care and rehabilitation facilities and new forms of living]. Hyg Med. 2018;43(1/2). German. Available from: https:// www.krankenhaushygiene.de/pdfdata/hm/2018_1_2_ Lebensmittelpapier.pdf

97. Kommission für Krankenhaushygiene und Infektionsprävention (KRINKO). Personelle und organisatorische Voraussetzungen zur Prävention nosokomialer Infektionen. [Personnel and organizational requirements for the prevention of nosocomial infections]. Bundesgesundheitsblatt. 2009;52(9):951-62. German. https://doi.org/10.1007/s00103-009-0929-y PMID:19690813

98. Kommission für Krankenhaushygiene und Infektionsprävention (KRINKO). Anforderungen an die Hygiene bei der medizinischen Versorgung von immunsupprimierten Patienten. [Requirements for hygiene in the medical care of immunocompromised patients.] Bundesgesundheitsblatt. 2010;53(4):357-88. German. https://doi.org/10.1007/s00103-010-1028-9 PMID:20300719

99. European Food Safety Authority and European Centre for Disease Prevention and Control (EFSA and ECDC). The European Union summary report on trends and sources of zoonoses, zoonotic agents and food-borne outbreaks in 2017. EFSA J. 2018;16(12):e05500. https://doi.org/10.2903/j.efsa.2018.5500 PMID: 32625785

License, supplementary material and copyright

This is an open-access article distributed under the terms of the Creative Commons Attribution (CC BY 4.0) Licence. You may share and adapt the material, but must give appropriate credit to the source, provide a link to the licence and indicate if changes were made.

Any supplementary material referenced in the article can be found in the online version.

This article is copyright of the authors or their affiliated institutions, 2021. 